\title{
Developing a Provincial Centralized Intake Process for a Knowledge Resource Service Part 2: Article Requests ${ }^{1}$
}

\author{
Michelle Turner and Marcus Vaska
}

\section{Introduction}

Knowledge Resource Service (KRS), part of the provincial Knowledge Management department of Alberta Health Services (AHS), is comprised of health library teams and consultants across Alberta. As mentioned in Part 1 of the article, "Developing a provincial centralized intake process for a Knowledge Resource Service Part 1: Literature Search Requests" [1], KRS connects AHS staff and healthcare providers with evidence-based resources and supports them in effective use of these resources to make evidence-informed decisions and to promote quality patient care. Document delivery service (DDS) is a key library function that supports the AHS initiative "to provide staff and physicians with information to better support decision making" [2].

When developing document delivery services, many libraries implement efficient resource sharing initiatives. The library literature describes catalogue sharing networks that are designed to minimize the cost and delivery time involved in transferring books [3, 4]. However, less has been written on centralizing article request intake and the electronic delivery facilitated by updates to the Canadian Copyright Act (section 30.2) [5].

Our new program centralizes article DDS intake and delivery to health care staff through virtual library services. AHS is comprised of more than 400 sites across the province. The more than 100,000 AHS staff members located within these sites are now served from a single virtual access point. In accordance with the description of a virtual library by Nievas et al., [6] "access to the most relevant information is democratized and centralized".

When the 19 previous hospital libraries (Table 1) were brought together as a provincial service in 2012, differences in service levels needed to be examined. A number of KRS working groups comprised of librarians, library technicians, information specialists, and managers were established for this purpose. The DDS subcommittee was formed in November 2012 under one such group, Research and Reference, to address differences in the provision of document delivery. The objective of the DDS subcommittee was to develop a single point of intake for receiving and processing article requests to provide a consistent, equitable service.

\section{Description}

Initially the DDS subcommittee surveyed DDS intake practices across the KRS sites. In one area, a prescribed web form was already in use. In other areas, article requests were submitted by email, giving clients a choice of which library to contact. A central article request web form was chosen as the preferred option for the new service.

To keep the web form as simple as possible, the DDS subcommittee determined the minimum amount of client information needed to deliver an article electronically: name, email address, and phone number (for follow-up, if necessary). We decided that the client's work site was not required; however, a field for the client's AHS zone (i.e., general location in Alberta) was included for evaluation purposes. To collect the article citations, we elected to use a single text box rather than separate fields (title, author, etc.) to allow the requestors to "cut and paste" from a variety of sources.

Considerable discussion went into determining the timeline for providing articles. Electronic delivery options have greatly reduced delivery time. Documents can now generally be delivered by email in about a day and a half compared with 4 days by mail [7]. From the client's perspective, sooner is always better. Nonetheless, in anticipation of the popularity of the new DDS, we did not want to offer a service level that we could not meet consistently. We thus added a "time needed by" field to allow the client to choose one of three options:

Michelle Turner ${ }^{2}$. Knowledge Resource Service, Tom Baker Cancer Centre, Rm CC116, 1331 - 29 Street NW, Calgary, AB T2N 4N2.

Marcus Vaska. Knowledge Resource Service, Holy Cross Site, 615A, 2210 - 2 Street SW, Calgary, AB T2S 3C3.

${ }^{1}$ This article has been peer reviewed.

${ }^{2}$ Corresponding author (email: mturner@ucalgary.ca). 
Table 1. List of Knowledge Resource Service Sites, 2012

\begin{tabular}{ll}
\hline Alberta Children's Hospital, & Medicine Hat Regional \\
Calgary & Hospital \\
Alberta Hospital Edmonton & Peter Lougheed Centre, Calgary \\
Centennial Centre for Mental & Queen Elizabeth II Hospital, \\
Health and Brain Injury, & Grande Prairie \\
Ponoka & Red Deer Regional Hospital \\
Cross Cancer Institute, & Rockyview General Hospital, \\
Edmonton & Calgary \\
Education Resource Centre, & Royal Alexandra Hospital, \\
Calgary & Edmonton \\
Foothills Medical Centre, & South Health Campus, Calgary \\
Calgary & Sturgeon Community Hospital, \\
Glenrose Rehabilitation & St. Albert \\
Hospital, Edmonton & Tom Baker Cancer Centre, \\
Holy Cross Touchdown Suite, & Calgary \\
Calgary & Women's Health Centre, \\
Kaye Edmonton Clinic & Calgary \\
\hline
\end{tabular}

- standard request (2-4 day delivery);

- rush request (1-2 day delivery); and

- urgent patient care request (same day delivery).

After a 3-month period, we reviewed these options. Based on client and KRS staff feedback, the choices were simplified to a standard request (1-4 day delivery) and an urgent patient care request (same day delivery). In our experience, the majority of articles arrive within one business day of being ordered. To provide excellent customer service without placing undue strain on external lending libraries, we developed an internal guideline to acknowledge all standard requests within one business day regardless of whether or not the article had been received.

Once the web form had been finalized, determining how the article requests would be received and answered then became the focus of the DDS subcommittee. We identified 19 library technicians and support staff with DDS training and pre-existing access to DOCLINE, our primary request system. These staff members, located in $13 \mathrm{KRS}$ sites across AHS, are referred to in-house as "DDS stewards" to engage staff in the goal of providing a seamless document delivery service directly to our clients.

Three scenarios for distributing requests among the DDS stewards were discussed by the DDS subcommittee. A gatekeeper or triage model was immediately rejected because it was deemed more efficient for one staff person to handle a request from beginning to end. A central library model whereby all DDS would be completed by one or more select KRS sites was also rejected due to the dramatic workload shift that this could entail. A rotating shift model was thus approved and further developed.

In the rotating shift model, two shifts were set up: 8:00 am to $12: 00 \mathrm{pm}$ and 12:00 pm to $4: 00 \mathrm{pm}$. Two stewards with the responsibility of monitoring and filling incoming article requests are assigned to each shift on a rotating basis. To ease workload during busy times and address scheduling concerns, a third, one-person shift was added from 10:00 am to 2:00 pm on Tuesdays, Wednesdays, and Thursdays. DDS stewards were consulted about shift preferences and currently average five shifts per month. Other work duties and time away affect the number of shifts handled by each steward. To manage workload, DDS stewards are encouraged to work with their shift partners (and subsequent DDS stewards, as necessary) to respond to article requests within established timelines while effectively balancing their other work responsibilities.

Because a provincial online intake form did not exist before the launch of the KRS web site in August 2013, a pilot program was not possible. Online and in-person training was given to introduce the new intake procedure. Training was supported by the creation of written guidelines and procedures. The DDS stewards adapted quickly, with much of the learning taking place while responding to actual client requests.

\section{Outcomes}

Since launching the provincial service in August 2013, we have filled more than 10,000 requests. Over 35,000 articles have been provided via link or PDF (according to copyright or licensing policies), indicating that a client requests an average of over three articles per transaction. Approximately $40 \%$ of all requests via the KRS web site (www.krs.albertahealthservices.ca) are for document delivery. The remaining $60 \%$ are literature search and reference requests.

In April 2014, KRS sent out a biennial survey to AHS staff. Two questions pertained to DDS:

(1) In the past 12 months, how frequently have you accessed ... a document (book or article) request?

(2) Please rate your level of satisfaction with ... a document (book or article) request

The online survey was distributed province-wide to health professionals, support staff, and physicians, and it was accessible on the KRS website over a 2-week period. A total of 888 responses to the survey were received, results that are generalizable to the entire population surveyed. Of the respondents, $97 \%$ stated awareness of DDS, with over $81 \%$ having used the service at least once during the previous year. With regards to appreciation of the service, $94 \%$ of respondents indicated they were satisfied or very satisfied with DDS [8]. We are gratified to see that initial response to the provincial document delivery service has been favorable.

In addition to the external survey, an internal audit was conducted to determine if service guidelines are being met consistently. With a focus on standard (i.e., 1-4 business day) requests, the questions included:

(1) Was the request acknowledged within one business day, either with the article(s) supplied or a note indicating that an order had been placed?

(2) Were the articles provided within four business days, or a status report sent to explain the delay?

These questions were designed to promote communication between management and the DDS stewards to further develop a sustainable, consistent level of service. 
Individual results were discussed with each DDS steward to allow the opportunity to address training needs and individual challenges. The data collected will serve as a baseline as we continue to improve workflow processes.

\section{Discussion}

The KRS team continues to develop as we learn and share the strengths that we each bring to the provincial service. Discussions around providing quality document delivery services are on-going and take into consideration existing expertise. As library websites improve and clients become more adept at finding materials themselves, the requests to libraries become more challenging. Clientsubmitted article requests may be incomplete, inaccurate, or desire hard-to-find grey literature. At KRS, we continue to expand and document best practices for article searching and ordering.

On-going training is necessary to stay abreast of evolving license agreements and copyright interpretations. We are in the process of developing FAQ lists as reference points for KRS staff and our clients. We also plan to investigate our licenses further to ensure that we are using our electronic collections appropriately and to their full potential.

An article request can be a gateway to library services by providing the first contact between a client and a library. Because requests can expand into technical questions and literature searches, DDS staff members require reference skills and an understanding of library processes as a whole. Regular KRS Technical and Support Staff Meetings provide a forum for the DDS stewards to discuss the challenges, best practices, and training needs listed above.

\section{Conclusion}

Designing a single point of intake for receiving article requests, then developing a standardized way of processing those requests has been a challenge - but one that has been made easier by the dedication to customer service shown by KRS staff. Although there is always room for improvement, the accolades and feedback from our users indicate we are taking steps in the right direction. As a collaborative team, we continue to work together to maintain our commitment to providing equitable document delivery service to all AHS employees across the province.

\section{References}

1. Vaska M, Aitken E, Varney J, Stevens S. Developing a provincial centralized intake process for a Knowledge Resource Service part 1 - literature search requests. JCHLA/ JABSC. 2014;35:124-127.

2. Alberta Health Services (AHS). Alberta Health Services Health Plan and Business Plan (2012-2015) [Internet]. 2012 Apr; [cited 9 Jul 2014] Available from: http://www.scribd.com/ doc/117278467/Ah-s-2012-to-2015-Health-Plan

3. Cook A, Smith DJ. The Ohio Library and Information Network: Resource sharing at its best. J Interlibr Loan, Doc Deliv \& Elec Res. 2011;21(5):219-225.

4. Pronevitz G, Horton V. Creating NISO's library physical delivery recommended practices. Collaborative Librarianship. 2012;4(2):67-75.

5. Canadian Copyright Act [Internet]. 2012 Nov; [cited 2014 Jul 9]. Available from: http://laws-lois.justice.gc.ca/eng/acts/ C-42/page-27.html\#h-33

6. Nievas RO, Cervi VP, Ramon EP, Suarez SS, Marin MC. Creation of the centralized document supply service of the virtual health sciences library of the Balearic Islands. 2010; [cited 2014 Nov 3]. Available from: http://eprints.rclis.org/ 18673/1/poster-Lisbon-sod.pdf

7. Hill TW, Roth KL. Electronic document delivery: A six-year study to benchmark the shift to electronic interlibrary loan in two hospital libraries. J Med Libr Assoc. 2009;97(1):54-57.

8. Alberta Health Services (AHS). 2013-14 Biennial Survey Final Report: Knowledge Resource Service. Alberta, Canada: Jensen-Ross, C and Hurrell, C. 